Int. J. Electrochem. Sci., 14 (2019) 3265 - 3280

International Journal of

ELECTROCHEMICAL

SCIENCE

WWW.electrochemsci.org

\title{
Ag/Au Modified Nafion Coated Glassy Carbon Electrode for the Detection of Metronidazole
}

\author{
Mohammad F. Khanfar ${ }^{1, *}$, Naela Al Absi ${ }^{2}$, Eyad S. M. Abu-Nameh ${ }^{2,}$,, Munib M. Saket ${ }^{1}$, \\ Natalie Khorma ${ }^{1}$, Raya Al Daoud ${ }^{1}$, and Nasim Alnuman ${ }^{3}$ \\ ${ }^{1}$ Pharmaceutical-Chemical Engineering Department, School of Applied Medical Sciences, German \\ Jordanian University, P.O.Box 35247 Amman 11180 Jordan \\ ${ }^{2}$ Department of Chemistry, Faculty of Science, Al Balqa Applied University, Al-Salt 19117, Jordan \\ ${ }^{3}$ Biomedical Engineering Department, School of Applied Medical Sciences, German Jordanian \\ University, P.O.Box 35247 Amman 11180 Jordan \\ "E-mail: mohammad.khanfar@gju.edu.jo (M. F. Khanfar); abunameh@bau.edu.jo (E. S. M. Abu- \\ Nameh)
}

doi: $10.20964 / 2019.04 .43$

Received: 10 December 2018 / Accepted: 5 February 2019 / Published: 10 March 2019

In pharmaceutical analysis, especially in Jordan, almost all of the attention is paid to the chromatographic and photometric methods of analysis. The utilization of electrochemistry as a tool for determination of the active pharmaceutical ingredients is not common. In this work, metronidazole (MNZ) was detected electrochemically in its aqueous buffered solution utilizing differential pulse voltammetry, which is one of the key electrochemical tools used for chemical analysis. For the detection purposes, nafion coated glassy carbon electrode was modified with gold, then silver by means of electrochemical deposition. The modified electrode has demonstrated significant performance toward the detection of metronidazole. Statistical evaluation of the reported performance shows that the detection is valid in the $1.00 \times 10^{-4}$ $1.00 \times 10^{-3} \mathrm{M}$ range with limit of detection equals to $5.87 \times 10^{-8} \mathrm{M}$ and limit of quantitation equals to $1.96 \times 10^{-7} \mathrm{M}$. The detection of metronidazole in solid pharmaceuticals provided locally was also investigated and recovery values in the $91-97 \%$ range were obtained. The modified electrode was also employed for the monitoring of metronidazole electrolytic degradation, usually detected by means of total organic carbon analysis or photometric instrumental methods. The utilized electrochemical monitoring have demonstrated efficiency that is comparable to the standard photometric method when the degradation was performed with platinum anode and boron-doped diamond cathode.

Keywords: Metronidazole, Modification, Differential Pulse Voltammetry, Scanning Electron Microscopy, Electrolytic Degradation 


\section{FULL TEXT}

(C) 2019 The Authors. Published by ESG (www.electrochemsci.org). This article is an open access article distributed under the terms and conditions of the Creative Commons Attribution license (http://creativecommons.org/licenses/by/4.0/). 